\title{
Conocimiento sociológico y planificación social: la relación teoría-praxis
}

\author{
Manuel Herrera Gómez *
}

\section{Sociología y política social: replantear una compleja relación}

La relación entre conocimiento sociológico y planificación social constituye un tema clásico que resulta difícil de afrontar. De todos es sabido que el nacimiento de la sociología está ligado a un objetivo: incidir en la sociedad para crear una «sociedad mejor». Tanto Comte como SAINT-SimON tenían en mente «planificar» el progreso. Esta idea también la encontramos en casi todos los clásicos de la sociología, buenos ejemplos son MarX, Durkheim, Spencer y Pareto. Sólo algunos, como es el caso de Weber y Simmel, se distancian de las necesarias implicaciones entre sociología y planificación social. Ahora bien, será con PARSONS cuando vuelva a cobrar actualidad la idea de una sociología como ciencia de los «sistemas sociales».

Por diversas razones, después de PARSONs las cosas se han complicado. En primer término habría que decir que sociología y política social interiormente adquieren una mayor complejidad, a la par que se distancian. En segundo lugar, no hemos de olvidar que cambia el clima cultural: cae la ideología del progreso como realización de un «plan perfectamente diseñado». Finalmente, hay que tener presente que, al considerar los acontecimientos sociales, los más próximos parecen ser más complejos que los lejanos; no en vano, asumen aspectos progresivamente más ricos y confusos, de tal forma que las circunstancias del momento histórico contemporáneo siempre son más difíciles de seleccionar.
En cualquier caso, el conocimiento sociológico no ha dejado de preguntarse: «¿Conocer para qué?». La respuesta a este interrogante es la siguiente: tiene que haber un impacto de la sociología en la realidad. «¿Qué impacto?». Ciertamente, éste es nuestro problema.

La expresión «tiene que baber un impacto» puede interpretarse de dos formas: a) como una afirmación descriptiva (cuando se constata que el conocimiento sociológico es siempre una definición de la situación en la que opera una influencia por la simple motivación que redefine el problema), o bien, b) como una afirmación normativa (cuando se asume que el conocimiento sociológico nace de un interés práctico y, por lo tanto, que la sociología siempre está encaminada a la acción y/o intervención social). En realidad, las dos modalidades suelen estar presentes de manera conjunta, y resulta muy difícil diferenciarlas. Sin embargo, la segunda perspectiva revela con mayor detalle cómo se introduce la idea de «plan» en la sociología.

Un teorema sociológico fundamental, que plantea el inicio del famoso círculo hermenéutico, es que el conocimiento sociológico, independientemente de sus motivaciones y objetivos, siempre modifica la realidad social. Sin embargo, la sociología presenta aspiraciones de horizontes más amplios: afirma que su conocimiento no se desarrolla sin que en la mente del investigador exista un «plan» sobre la realidad, un plan de conocimiento encaminado a la intervención. De esta forma, el concepto de «planificación», en sentido estricto, entra normativamente en la relación entre sociología y política social.

A pesar de la evidencia de esta relación, desde los años ochenta se difunde una impresión que, a decir verdad, no es nueva. Me refiero a la idea de que la sociología no es muy 
útil en el «plano operativo». Dicho en otros términos y de forma contundente, a la sociología se le reprocha el ser un conocimiento incierto, «distorsionado», precario, poco útil para la consecución de los objetivos de la intervención social. Por otra parte, no hemos de olvidar que, frecuentemente, las políticas sociales son formuladas e implementadas sin tener en cuenta las aportaciones que proceden de la investigación sociológica empírica.

Lo cierto es que nunca ha sido fácil mantener conexiones significativas entre pensamiento sociológico y política social. Sin embargo, en la actualidad, por diversas razones de diferente carácter, las dificultades parecen aumentar.

La intención que se esconde detrás de estas páginas no es simplemente elaborar un listado de las múltiples y complejas «causas» que dificultan las relaciones entre sociología y política social. Más bien, se intenta reflexionar sobre la dinámica de estas relaciones. El objetivo es, por una parte, aclarar las dificultades que la sociología encuentra en su utilidad operativa, por otra, analizar aquellos motivos que hacen que las políticas sociales no saquen todo el partido que se puede extraer del conocimiento sociológico. Por tanto, se pretenden sacar a flote aquellas condiciones que precisa una eficaz relación entre sociología y programación social en el contexto de una sociedad compleja. Para lograr este objetivo puede ser útil recordar aquellos factores que, tanto por parte de la sociología como de la política social, han debilitado sus relaciones.

1. En sociología. Desde el punto de vista epistemológico y cognitivo, especialmente a partir de la década de los sesenta, en la sociología se introduce la siguiente idea: la realidad social no se puede conocer «como tal», sólo se la conoce cuando «está becha», incluso sólo mediante el pensamiento. Al no ver la mayor parte de los sociólogos en que consiste la realidad de lo social, contemplada generalmente como pura contingencia o como subproducto de otras realidades (económicas, psíquicas, culturales, biológicas...), la expresión «conocimiento de la realidad social» se hace fugaz, incierta, inconsistente. No es una casualidad que la crisis del Estado de Bienestar sea paralela a la crisis del positivismo y al éxito del neo-constructivismo y del convencionalismo sociológicos.

2. En la politica social. Las doctrinas de política social se han encontrado ante una crisis, cada día más evidente, tanto en términos de apoyo idológico (del socialismo, aunque también del liberalismo, etc.), como en términos de implementación y eficacia de las intervenciones sociales de bienestar. Si se contempla en clave sociológica, la crisis de la planificación social no tiene su origen en el dominio de una ideología (la neo-liberal o conservadora) sobre otra (la socialdemócrata, laboralista, socialista..), ni en razones económicas (falta de recursos materiales y financieros) o administrativas (dificultades organizativas), sino en un hecho más profundo e intrínseco a las sociedades complejas: la pérdida de normatividad (P. DonaTI, 1985).
Con menor frecuencia las políticas sociales son elaboradas por el sistema político-administrativo como centro de decisiones autónomo. Cuando lo son, generalmente las decisiones no pueden ser activadas, $y$, donde se trata de implementar programas pre-definidos, emergen crecientes efectos inesperados y perversos.

Estos dos conjuntos de factores (epistemologías débiles o auto-referenciales y pérdida de normatividad de los sistemas sociales y culturales) se encuentran íntimamente conectados. Si se sigue la aproximación sistémica de LUHMANN, que asume la no percepción directa entre los sistemas, se hablará de «simultaneidad de acontecimientos» y de «continuum de materialidad» en las relaciones entre los dos sistemas (el del conocimiento sociológico y el de la política social). Sin embargo, se puede decir algo más. Me refiero a una «lógica» general que los comprende: la lógica de las sociedades llamadas post-modernas.

Las características de esta lógica pueden quedar sintetizadas así:

a) En negativo, la fluctuación del conocimiento sociológico y de la política social.

b) En positivo, la emergencia de una nueva complejidad relacional, con todos los riesgos, potencialidades e innovaciones que conlleva.

Estas dos características definen las condiciones desde las que es posible pensar la planificación social, más allá de los rígidos esquemas tradicionales.

a) En el clima post-moderno: por una parte, se afirma que la sociología no tiene un alcance cognitivo, ni normas objetivas independientes del observador (es decir: su conocimiento no contiene «verdades», ni indicaciones de «deber ser», siendo estos caracteres resultado de la autonomía de los sistemas observados); por otra, se considera que las políticas sociales (a las que corresponden los caracteres de la normatividad política) no pueden ser formuladas, ni activadas según valores o normas; ni donde son establecidas por la comunidad política (el Estado), ni donde son formuladas por los singulares actores («politicos»); las «praxis» son, y necesariamente tienen que ser, contingentes, no inspiradas en intenciones, sino en estrategias de ganancia combinatoria que rechazan programas normativos.

La investigación sociológica orientada a la operatividad debería abandonar la esperanza de incidir en la realidad social, al menos en el sentido de conducirla desde cualquier parte (prevista). Como investigación finalizada, a lo sumo podría concebirse como auto-delimitación de límites por su conocer-obrar (por ejemplo, como investigación-acción). En síntesis, la investigación finalizada no podría ser más que una selección «inteligente» de lo que no se puede conocer y de lo que no se puede hacer. 
El resultado es, por una parte, mantener la impresión de que la sociología no tiene nada que decir acerca de las posibles soluciones de los problemas sociales, ya que es incapaz de dar sugerencias prácticas como conciencia crítica de la sociedad; por otra, se incentiva la sensación de que las políticas sociales siguen formulando programas irrealizables, girando en el vacío.

b) Pero no es así. Cuando son expresadas como juicios omni-comprensivos, las conclusiones extraídas son apresuradas y pesimistas: nacen y se difunden en los que no consiguen comprender la magnitud de los actuales acontecimientos. Asistimos a importantes innovaciones que caminan -y ésta es mi hipótesis- hacia una «programación posible», entendida como modalidad para gestionar las relaciones sociales.

No es el objetivo de estas páginas resumir y criticar la literatura existente. Más enriquecedor es diseñar un marco teórico para la comprensión de las relaciones entre sociología y política social desde una óptica más positiva, en un momento histórico de profunda redefinición de la situación. Dicho en otros términos, se asume una actitud de observación de la realidad social que la interpreta y describe como apertura de nuevas posibilidades.

Desde esta óptica, puede ser interesante considerar la diferencia entre la situación en España y en los países anglosajones. En estos últimos, la sociología y la política social se distanciaron hace mucho tiempo: mientras que la sociología implica la investigación empírica con objetivos cognitivos, la política social se ocupa del análisis y el establecimiento de las directrices normativo-operativas (vinculadas tanto a la confrontación entre ideologías como al organigrama de la social-administration). PAR. SONS fue el símbolo de esta separación cuando señaló que la sociología debía diferenciarse tanto de la filosofía social, como de los problemas sociales. En esta línea se ubican actualmente la mayor parte de los sociólogos norteamericanos (N. J. SMEL. SER, 1988).

Los intentos de conexión no faltan, más bien cabría decir lo contrario. Algunas disciplinas, un buen ejemplo es la policy analysis, nacieron con la pretensión de conectar relaciones tan diferenciadas. Sin embargo, estas disciplinas están muy lejos de ofrecer una conceptualización adecuada del complejo de las relaciones: más bien se centran en algunas relaciones (por ejemplo, la incidencia de las políticas estatales en determinadas cuestiones). El resultado es la multiplicación de las disciplinas sobre la planificación social, y no un salto de calidad en la forma de entenderla. Estamos ante campos de estudio que se añaden a otros, sectores que se diferencian de otros por una diversa combinación de factores, en un marco general vinculado al empirismo, el utilitarismo o el pragmatismo.

Por razones históricas demasiado complejas como para entrar en ellas, en España la sociología y la política social todavía no se han diferenciado de manera relevante, siendo su situación la de una mezcla confusa.

Si se considera la relación cognitivo-operativa (usociología/política socials como sistema), ni la situación española (de escasa diferenciación), ni la vía anglosajona (de creciente diferenciación pragmática) constituyen soluciones adecuadas a las necesidades que emergen a partir de los años ochenta. Estamos ante necesidades que requieren, al contrario que lo planteado por la vía anglosajona, nuevas y significativas integraciones, mientras, a diferencia de lo que sucede en España, necesitan sucesivos procesos de diferenciación.

La incapacidad para comprender estas nuevas exigencias constituye el núcleo de la crisis de la investigación sociológica aplicada y, en parte, explica las deficiencias y la relativa marginación. La misma incapacidad revela las dificultades para la realización de las políticas sociales, que, justamente por la falta de un adecuado apoyo sociológico, se refugian en las viejas corrientes del economicismo, de la ideología o de prácticas incrementalistas «incoberentes».

Dicho brevemente, la tesis que se expone en estas páginas sostiene que: si se quiere comprender el actual camino de la investigación finalizada en las ciencias sociales, bay que utilizar una aproximación que sepa prever al mismo tiempo una mayor diferenciación y una mayor integración entre sociologia y politica social.

El hilo conductor de las argumentaciones que se presentan es el siguiente: afrontamos la relación entre conocimiento sociológico y política social dentro de una configuración general que permite insertar los elementos del contexto y las variables de intervención, así como la evaluación de las diferentes aproximaciones que actualmente se disputan el campo de la planificación social.

El esquema que se propone (fig. 1) adopta una perspectiva que ayuda a tratar las interacciones entre sociología y planificación social contemplando los conflictos que van de arriba hacia abajo (downwards conflations) (tipo a), los conflictos centrales (central conflations) (tipo b) y los conflictos que van de abajo hacia arriba (upwards conflations) (tipo c), contenidos en los diversos modelos de programación. Al mismo tiempo, nos permite relacionarlos con un modelo más comprensivo que denominamos morfogenético relacional (tipo d) ${ }^{1}$.

En primer lugar se elaborará un marco conceptual general de los diversos paradigmas que ayudará a distinguir: el paradigma tradicional del realismo positivista, el paradigma del constructivismo, el paradigma del convencionalismo y el paradigma relacional. Se intentará hacer una exposición y una evaluación de su capacidad de gestión de la relación entre conocimiento sociológico y programación social.

A continuación se abordará el sentido con el que hay que entender la interacción entre conocimiento sociológico y política 


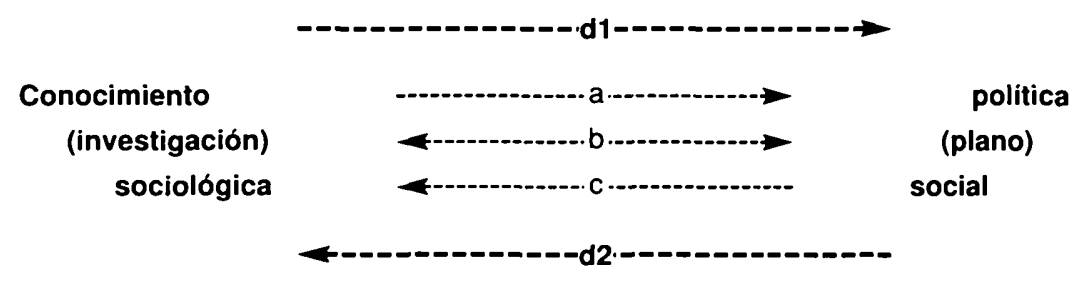

Linea a: conflictos que van de arriba abajo (downwards conflations).

Linea b: conflictos centrales (central conflations).

Linea c: conflictos que van de abajo arriba (upwards conflations).

Linea d (d1 y d2): planteamiento relacional morfogenético.

social como «relación supra-funcional de reflexividad reciproca». Finalmente se planteará una visión de la programación social como relación entre conocimiento e intervención que se configura como construcción de sistemas ODG (observación-diagnóstico-guía relacional).

\section{Cuatro paradigmas de acoplamiento entre conocimiento sociológico y política social}

Tradicionalmente, el conocimiento social se ha concebido como anterior e independiente de la práctica social (intervención o política social). Desde COMTE a PARSONS, se asume que plan e intervención se desprenden del conocimiento. Ante las dificultades y debilidades de este paradigma, se adoptó la postura inversa: se asume que el conocimiento deriva de la práctica y del plan de acción. La planificación es presentada como un reflexionar interactivo sobre la práctica y la intervención. El resultado es el siguiente: si el modelo tradicional incurría en una programación rígida, la postura contraria ha producido la anulación de todo programa, el conocimiento ha perdido su distancia de la praxis, aún más, se ha vuelto mera praxis.

En la actualidad es necesario comprobar si es mejor ubicar conocimiento sociológico e intervención en relaciones de reciprocidad, según diferentes y autónomos momentos, aunque siempre interactivos (como interacción que tiene una duración en el tiempo) (I. Pons, 1993: 8). No hay conocimiento sin intervención y viceversa. Cada uno progresa en la medida en que se sitúa en distinción interactiva con el otro. Es decir: no se trata de «conocer para actuar», ni «actuar para conocer», sino «conocer y actuar conjuntamente», interactivamente. Aún más: la interacción no puede ser simultánea, sólo puede realizarse en el tiempo, mediante fases sucesivas. Una planificación implica tres fases que se repiten cíclicamente: una fase de conocimiento del problema y proyecto de la intervención (tiempo T1), una fase de acción-experimentación (tiempo T2) y una fase de elaboración atenta al fenómeno de «emergencia social» (tiempo T3), que a su vez es condición para iniciar el ciclo de programación sucesivo.

Lo dicho conlleva distinguir la programación que sigue una aproximación morfogenética de las programaciones unidireccionales (el conocimiento determina la intervención o al revés) y de las programaciones interaccionistas (o teorías de la estructuración) que incurren en una fusión de la interacción local (central conflation).

El retorno de los planteamientos neoliberales ha difundido la idea de que las relaciones entre sociología y política social son fragmentadas, descentralizadas, progresivamente más aisladas entre sí. Sin embargo, desde la perspectiva morfogenética emerge la necesidad de replantear las relaciones entre sociología y política social en el sentido de una creciente coimplicación. La identidad de ambas es «función de una reciproca reflexivi$d a d{ }^{2}$, que al mismo tiempo es diferenciadora e integradora según formas diversas.

La sociología se hace «más sociología» distinguiéndola de la política social. También, al contrario, la política social adquiere mayor identidad distinguiéndose de la sociología. Pero, si cada una fuese independiente, simplemente tendríamos una fuerte separación entre conocimiento e intervención. Conocer para intervenir implica un acoplamiento estructural que permita una «resonancia» mutua. Es necesario comprobar en qué medida y cualidad tal resonancia conlleva cualquier forma de «reciprocidad» (de recíproco relacionamiento de relaciones). El conocimiento sociológico avanza cuando la política social es 
reflexiva y, viceversa, la política social progresa cuando puede contar con una sociología lo suficientemente reflexiva.

En los años ochenta, las viejas relaciones se presentan impracticables e inconsistentes:

a) Entre la epistemología sociológica tradicional (de matiz positivista) y los planteamientos (y los programas) condicionales de política social.

b) Entre la epistemología del constructivismo autoreferencial y los planteamientos del incrementalismo evolutivo (selectivo, improbable).

El primer modelo asume que el conocimiento sociológico determina la política social (downwards conflation). Por su parte, el segundo defiende que entre conocimiento sociológico y politica social existe una interacción horizontal simultánea (central conflation).

Se abre camino un tercer paradigma:

c) El paradigma del convencionalismo sociológico, basado en el individualismo metodológico, que se acopla con una política social de privatización («liberalización», desregulation, es decir, una programación construida a partir de un «interaccionismo local», según mecanismos atemporales, que aluden a una idea de «mano invisible» de la sociedad, y no sólo del mercado como encontramos en A. SMrTH).

Este paradigma también presenta una capacidad limitada, ya que está basado en una hipótesis tan irreal como las anteriores: defiende que las políticas sociales están hechas de individuos particulares o actores, de ellos hay que extraer el conocimiento sociológico de los fenómenos y las correspondientes medidas a activar (la política social, como expresión de elecciones individuales, revela, desde el punto de vista sociológico, una upwards conflation entre los términos de la relación conocimiento/acción-intervención).

Ha llegado el momento de un cuarto paradigma:

d) Nos referimos a aquel que combina una epistemología morfogenética con un planteamiento relacional. Dicha combinación intenta evitar las modalidades de fusión precedentes, a fin de mostrar que, entre sociología y política social, existe una verdadera relación social que introduce en el juego relaciones sociales ${ }^{3}$.

A continuación se presenta un cuadro (fig. 2), que se sirve de tipos-ideales elaborados con pretensiones heurísticas. Desde la hipótesis de que la relación conocimiento sociológico/intervención social puede ser descrita como sistema, el esquema indica cuatro modalidades de acoplamiento estructural que, con posterioridad, serán abordadas.

Cada paradigma será tratado de la siguiente forma: explicar cómo se concibe el conocimiento sociológico y, paralelamente,
Figura 2

Cuatro modalidades de acoplamiento estructural

entre conocimiento sociológico e intervención social

\section{EPISTEMOLOGIA SOCIOLÓGICA}

A Realismo positivists.

La redided social esti objetivamente escrita en los fenómenos.

B. Positivismo constructivista.

La realidad social es la misma obsenvación, o bien es la construcción de sistemas autoreferenciales.

\section{Convencionalismo.}

La realidad social es proyección de los individuos y de sus elecciones, opciones, acciones.

D. Morfogenético.

La realidad social es relación, es decir, relacionalidad como fenómeno sui generis de naturaleza semergentes. autopoiéticos operativamente cerrados y
PLANIFICACIÓN SOCIAL

A. Condicional

La politica social debe seguir las aleyesos de la sociedad.

B. Incrementalismo evolutivo.

La politica social es intervención para reducir-e-incrementar la complejidad mediante selecciones oportunistas improbables.

C. Privatización.

De la mano invisible a la desregulación, la política social es intercambio e uinteracción locals.

\section{Relacional.}

La politice social es interacción capaz de captar reflexiva y adecuadamente: planteamiento de redes y sistemas ODG. cómo se pretenden formular e implementar los programas de política social. Utilizaremos el ejemplo de la familia, particularmente interesante porque la política social y la planificación como expresión de proyecto constituyen una respuesta a las necesidades de las familias.

\subsection{El paradigma del realismo positivista (programación condicional)}

Hasta la década de los sesenta, en sociología ha prevalecido un modo tradicional de conocimiento basado en un realismo ingenuo. Si nos centramos en el caso concreto de la familia, se decía que era una realidad objetiva que debía conocerse en su estructuras, comportamientos, condiciones y transformaciones como algo «dado» (externo al sujeto conocido y socialmente vinculado).

Al revisar las investigaciones empíricas de los años cincuenta y sesenta, concretamente las más orientadas a la política social, se puede comprobar que el objetivo de los sociólogos era «descubrir» una entidad palpable, una «cosa» que ciertamente cambia, pero que podía y debía ser orientada a un conjunto de factores visibles o, por lo menos, mensurables. Desde el punto de vista epistemológico, esta aproximación aún está presente en gran parte de los estudios demográficos ${ }^{4}$. Buena parte de la sociología también sigue razonando por modelos como si fuesen cosas (se discute si la familia, entendida según un cierto «modelo» tradicional, existe o ha dejado de existir...).

Desde este paradigma, ¿cuál es la concepción de lo social? Grosso modo se puede decir que es el criterio de las funciones 
asumidas por la sociedad. Por ejemplo, en el caso de la familia, se dice que es social en cuanto que es la «célula» de la sociedad que asume ciertas funciones fundamentales de reproducción. Este es el comienzo de la teoría evolucionista que, al inicio de la historia, contempla una familia que prácticamente coincide con la sociedad; posteriormente se irá especializando en determinadas funciones, progresivamente más «reducidas». Aunque sea autoreferencial (lo social es definido como función social), este criterio está íntimamente ligado con lo no-sociológico. Volvamos al ejemplo de la familia: ésta es considerada natural (biológica), y el sistema cultural, en cuanto que es variable, es interpretado a partir de las interrelaciones con el sistema de la personalidad.

La sociología parsoniana ha constituido un emblema sobre este tema, ya sea como teoría del orden, ya sea como teoría del cambio social que ha producido un específico conocimiento. Por ejemplo, la familia como pattern nuclear aislado, estructurado según los ejes del poder (generacional: de arriba-abajo) y de la división del trabajo (entre los sexos: instrumentalexpresivo), pensado como «bomogéneo» a la sociedad industrial metropolitana.

En cuanto perspectiva sociológica, este paradigma asume un planteamiento condicional de la política social. Presupone una concepción normativa del orden social. Si retomamos de nuevo a la familia, veremos que ésta es objeto de la política social en cuanto unidad-lugar-esfera de asistencia para que pueda ser «funcional» a la sociedad. La política social es considerada como el instrumento de enlace orgánico entre familia y el resto de los sistemas sociales, en cuanto que elimina la desviación y la inadaptación.

La investigación aplicada de los años cincuenta y sesenta produce este tipo de conocimiento cuando, por ejemplo, con intentos emancipadores o de cambio dialéctico, se ubica en una perspectiva que presenta presuposiciones generales de carácter marxista (por ejemplo, L. BALBO, 1977).

Muy cercana a este paradigma es una forma de considerar la planificación social según programas condicionales. Se ha pensado que la familia pudiera estar influenciada por el sistema político-administrativo según valores y normas condicionales, es decir, según programas basados en el «si...entonces» (si se presenta determinada circunstancia $X$, se aplica la intervención Y). Los programas de política social eran programas de «planificación» de la familia, en el sentido de un conjunto de fines y normas orientados a elaborar un modelo de familia homogéneo con los diversos tipos y fases del Estado de Bienestar. Especialmente en Europa, esta aproximación de política social, con todas sus modalidades, ha tenido muchas y concretas formulaciones. Pensemos en los programas encaminados a:

- La igualdad entre hombre y mujer (como cónyuges en la familia, como trabajadores en el mercado y, en general, como ciudadanos).
- Los derechos de los hijos menores (políticas para la infancia).

- La lucha por eliminar las familias pobres y marginadas (por ejemplo, familias numerosas y/o con miembros socialmente débiles).

Todas las políticas económicas keynesianas y los sistemas de seguridad social nacidos a partir de Lord BEVERDGE y sus seguidores han pensado y actuado en este marco. En el caso concreto de la familia, las políticas sociales de los años sesenta y setenta creían poder dirigir y controlar a la familia por medio de normas políticas y administrativas.

La formulación de las políticas sociales tenía lugar a partir de un centro/vértice, siendo posteriormente desarrolladas en las comunidades locales. La implementación se veía como un problema ejecutivo. La evaluación del impacto apenas se tenía presente, como si lo social se rigiese por un principio de casualidad lineal o multi-lineal. La emergencia de obstáculos o de efectos inesperados/perversos se consideraba una complicación más que podía superarse mediante posteriores indicaciones normativas o con una transformación de éstas.

\subsection{El paradigma constructivista (programación incrementativa)}

Las críticas respecto al paradigma positivista aumentan en los años setenta. El resultado ha sido la emergencia de otros paradigmas, de diverso tipo y orígenes, con el siguiente denominador común: poner de relieve un punto de vista constructivista que niega la precedente distinción directriz.

Lo social es presentado como emergencia interactiva de tipo comunicativo, siempre interna a la sociedad, de la que nadie escapa ${ }^{5}$. A diferencia del anterior paradigma, lo social no obedece ni a una lógica natural o histórica predefinida (por ejemplo, según universales culturales, como el de la familia nuclear, o según los determinismos marxianos entre estructura y superestructura), ni a un requisito previo estructural-funcional (del tipo ÁGIL). La distinción directriz es la siguiente: una concepción comunicativa de lo social. Desde esta concepción, lo social es lo que permite la continuidad de la comunicación, mientras que lo no-social es lo que la interrumpe.

Retomemos el caso de la familia: se la define a partir de sus comportamientos y representaciones, según un código simbólico relativo, y no por lo que hace para la sociedad, ni según lógicas o prerrequisitos estructurales. La familia se presenta como una pura construcción social que «se bace a si misma».

Desde estos postulados se han producido nuevos e interesantes conocimientos que no es necesario recordar. Brevemente podemos decir que su originalidad está en haber captado la creciente autonomía de las relaciones sociales (por ejemplo, 
familiares) como relaciones comunicativas. El resultado es contemplar en los fenómenos sociales unas relaciones fluctuantes que fundamentan su dinamismo morfogenético en la debilidad de los acoplamientos estructurales. Por ejemplo, un niño puede vivir más frecuentemente con adultos que no son sus padres biológicos, las parejas familiares pueden no ser ya heterosexuales, etc.: se habla de «fragmentación», pero también se podría hablar «fluctuación» de la familia.

Se ubica en estos planteamientos la consideración (y reducción) de la familia (y del ciclo de la vida familiar) como una intersección de estrategias individuales (G. ELDER, 1984). La familia es interpretada como un set o haz de relaciones (parejas de relaciones) variables en función de trayectorias individuales contingentes, que están condicionadas (estructuradas) por determinados factores: edad, género, etc. (C. SARACENO, 1986).

El resultado ha sido el siguiente: la sociología ha podido conocer la realidad social de la familia en la medida en que ha tomado como eje el carácter operativo de la comunicación: lo social es lo comunicable o comunicado, lo no-social es el no-comunicable o no-comunicado.

Desde estas premisas se derivan redefiniciones radicales del objeto social. En el caso de la familia, ésta es reformulada como intersección de trayectorias individuales en el ciclo vital ${ }^{6}$. En las posiciones más explícitas, se deben abandonar completamente los criterios normativos precedentes. Por ejemplo, hay que dejar el modelo de ciclo «de vida familiar» en cuanto que, bajo la nueva luz cognitiva, éste contiene presuposiciones no apropiadas, que ya no son vinculantes: en concreto, se asume que existe una familia que vive en el tiempo, una familia que atraviesa fases de crecimiento y restricción, como un ser que nace, crece y muere.

También éste es el destino de las instituciones sociales: se diluyen sus límites. Concretamente, la familia desaparece como institución social (N. LUHMANN, 1989: 221-232). Son necesarias nuevas distinciones. Emerge la exigencia de un nuevo planteamiento.

Similar a este paradigma es una forma de concebir la planificación social a partir de programas evolutivo-incrementales. La perspectiva específica a la que alude tal actuación es la de un incrementalismo selectivo oportunista. Si en la precedente perspectiva la política social es un sistema general de acción (por ejemplo, todo el complejo de las políticas para la familia), capaz de condicionar según cualquier «programa» normativo, en la perspectiva incrementativa se considera que el «modelo racional» de política social según programas condicionales es absurdo desde el punto de vista sociológico, ya que:

a) En el nivel cognitivo reduce a priori las posibilidades del análisis funcional.

b) En el nivel operativo plantea umbrales arbitrarios (en cuanto predefinidos) a la política social ${ }^{7}$.
La novedad que el planteamiento constructivista autorreferencial introduce en el conocimiento sociológico alude a nuevos temas cognitivos, apoyados en un específico aparato metodológico más sofisticado que el precedente. Sobre los aspectos metodológicos no es posible extendernos más. Respecto a los elementos cognitivos nos limitaremos a subrayar dos:

I. El punto de partida es considerar problemática la observación, asumiendo que los sistemas sociales que observan y son observados no son recíprocamente transparentes. Por ejemplo, quien observa la familia, en realidad no puede «comprenderla». El inicio de un posible conocimiento está en advertir la no autotransparencia.

II. Se continúa considerando problemático el «diagnóstico» (descripción de las condiciones según la distinción normalidad/patología), asumiendo que la evaluación del sistema que es observado es algo que el sistema que observa no puede hacer sólo a partir de sus conocimientos. Debe tener en cuenta el autodiagnóstico del sistema que es observado, de su autoobservación y evaluación. En el ejemplo de la familia nos encontramos ante la siguiente formulación: hacer un diagnóstico sobre la condición social de una familia (normal o patológica) quiere decir negociar con ella su definición (autorreferencial) de la situación.

A medida que se descubren los límites de la aproximación precedente, se han desarrollado programas de política social evolutivo-incrementales. En Estados Unidos prevalecía este procedimiento debido a la propia configuración del Estado de Bienestar en este país. Un modelo que presenta numerosas variantes (muddling through, mixed scanning, policy by objectives, etc.).

No más normas a aplicar, sino objetivos pragmáticos a perseguir evolutivamente (lo que no quiere decir necesariamente según modelos evolucionistas), de forma incrementativa. Al principio de los setenta, la sociología marxista propuso una lectura de este paradigma como crisis management de tipo conservador ${ }^{8}$. Con posterioridad, resultó evidente que el cambio de los modelos condicionales por modelos evolucionistas de tipo oportunista ${ }^{9}$ se debió a factores de mayor y diversa complejidad por parte de los sistemas societarios avanzados. Ahora bien, los teóricos de la complejidad no reconocen los fundamentos y las referencias neoliberales de su forma de observar la realidad.

Detrás de este cambio se esconden diversos factores de los que conviene subrayar tres:

1. En la formulación de los objetivos de los programas de política social, la progresiva fragmentación de la realidad social ha impuesto una creciente generalización de los valores a perseguir. Por ejemplo, la emergencia de una mayor variabilidad de las formas familiares ha significado una generalización del concepto de familia. 
2. Al ser más evidente la incapacidad de las burocracias públicas para adaptarse a los procesos de modernización, en la implementación de los programas ha sido necesario huir de la jerarquización y tender hacia la flexibilidad y la auto-organización.

3. En función de las características intrínsecas del nuevo esquema de política social (predominio de los fines sobre las normas, redefinición de la configuración organizativa como sistema flexible-finalizado y no jerárquico-burocrático), se ha tenido que introducir la evaluación de los resultados (outputs) y del impacto (interdependencia de los efectos) en los programas (entendidos como decisiones).

En el caso de la familia, el resultado ha sido una fuerte expansión de los programas de bienestar, a la par que una creciente diferenciación de los mismos. Aún más, detrás de este cambio de programas y de concepción de la política social, en el caso de las políticas familiares el objeto destinatario de estas políticas ha desaparecido. Las políticas sociales de tipo oportunista han diluido la familia (más concretamente, su representación institucional).

Paralelamente, en el terreno de las políticas sociales se han revelado los siguientes fenómenos:

1. La generalización de los objetivos de «bienestar» ha trasladado a una abstracción de las referencias conceptuales (por ejemplo, del concepto de familia), de tal manera que parecen haber perdido cualquier valor no oportunista. De hecho, actúan como «interruptores» que abren y cierran las medidas de bienestar (los entitlements) teniendo especialmente en cuenta factores políticos y económicos (las repercusiones electorales, las condiciones de la economía y de la deuda pública, las presiones de los lobbies).

2. La autonomía de las burocracias públicas (de los servicios estatales o formales) se ha traducido en un creciente cierre autorreferencial: los problemas internos de las organizaciones públicas de bienestar tienen prioridad sobre las prestaciones que deben ofrecer a los usuarios.

3. En situaciones de creciente complejidad, el análisis de las interdependencias y del impacto resultó implanteable. A pesar de los intentos constructivistas por introducir reflexión y reflexividad en su planteamiento, el gap se queda sin solucionar. Aún más: para una sociedad que se concibe y se estructura normativamente como arriesgada ${ }^{10}$, este análisis se presenta como una paradoja, un problema sin solución.

Al final, la multiplicación de programas para diversos sujetos y necesidades en el marco de las políticas familiares (la infancia, la mujer, la tercera edad, los minusválidos, y todo un conjunto de categorías, según variables como la edad, el género y las situaciones profesionales o económicas) ha tenido un éxito paradójico: la familia ba desaparecido. Mejor aún: se ha fragmentado y diluido de tal manera que en la actualidad es imposible, dentro de este paradigma, encontrar una definición de consenso generalizada.

En este marco, la política de la familia debe ser despolitizada. Hecho éste que revela las fuertes contradicciones que están presentes en el diseño de las propias políticas familiares.

El problema de fondo de las políticas sociales hodiernas, que intentan formular y aplicar programas con el menor número posible de efectos perversos, está en el hecho de actuar a ciegas: se camina sin tener, ni querer, alguna forma de familia como valor.

La referencia al «hogar doméstico», definido como el conjunto de aquellos que duermen bajo el mismo techo (convivencia como buosebold, ménage) no constituye una solución. No dirime las cuestiones inherentes a la titularidad de los derechos de ciudadanía. Si los derechos pertenecen a los individuos, ¿cuál es el lugar de la familia en el Estado de Bienestar? Si, por el contrario, la familia tiene derecho de ciudadanía, ćqué requisitos debe tener tal familia para que pueda ser considerada sujeto responsable de específicos derechos-deberes hacia la colectividad?

Incluso donde los derechos-deberes sociales sean reconocidos sin relación a la definición legal de familia (aquella fundada en el matrimonio), persisten los problemas: por ejemplo, saber si y cuál es la reciprocidad que el Estado promueve entre las partners, con qué legitimación y qué medios, qué relaciones entre familia de hecho y Estado fiscal, qué efectos de las prestaciones de bienestar a un núcleo familiar podrán modificar su composición de hecho (número y variabilidad de los componentes) en relación a los beneficios obtenidos.

En resumen, el Estado social debe interrogarse respecto a qué solidaridad está produciendo en lo social. Debe preguntarse si sus actuaciones favorecen la autonomía o la dependencia de los sujetos. Debe evaluar si el igualitarismo individualista que lo caracteriza operativamente afecta negativamente no sólo a los mundos vitales de las familias, sino también a sí mismo, a sus premisas, a su forma de afrontar los problemas sociales sin resolverlos.

El planteamiento evolutivo-incremental de tipo oportunista no parece conducir muy lejos. Parece generar más problemas de los que soluciona. Si las intervenciones que se pueden activar son improbables, inciertas y autorreferenciales, ¿cómo se pueden orientar las políticas sociales para que sean eficaces?

Para este planteamiento, las políticas familiares tan sólo pueden incrementar selectivamente las posibilidades, caracterizadas por la improbabilidad. De esta forma se deduce que las políticas familiares consisten en dar a las familias (autocertificadas como tales) lo que piden.

A largo plazo, el paradigma constructivista no conduce a nada, en el sentido de que no ayuda alcanzar un estado pre-es- 
tablecido de las cosas. Toda intervención revela límites estructurales que representan un verdadero obstáculo para el que quiera seguirlos hasta el final. Quien ha puesto en marcha una política social concebida de esta forma se ha encontrado como «hijo de nadie»: al desaparecer los valores (por ejemplo, la justicia distributiva), también desaparece la capacidad de evaluar estados diferenciales de cosas.

A pesar de ello, se introducen innovaciones que tratan de encontrar una salida a la desnormativización de las políticas sociales. Estamos ante innovaciones que emergen para dar una respuesta a los inquietantes interrogantes que nacen en ámbito cognitivista. Veámoslas brevemente:

1. Si el conocimiento depende del observador (que no significa subjetividad sino que la observación depende de la configuración del observador), ćcómo se puede solucionar el problema del no-conocimiento y de la no-comunicabilidad de las necesidades de quien se encuentra en condiciones socialmente frágiles, marginales, patológicas, estigmatizadas, problemáticas? Se abre camino la idea de que la respuesta debe ser consciente de la no transparencia de los sistemas (programas) que observan la realidad social a cambiar.

2. Si el diagnóstico del experto choca con el del sujeto destinatario de la intervención, ccómo se puede llegar a un diagnóstico no arbitrario y más eficaz? Se abre el camino la idea de que el problema de los diagnósticos diferenciales debe encontrar respuestas mediante un nuevo diálogo entre el código simbólico del «experto» y el autodiagnóstico de los sujetos que necesitan ayuda, discutiendo y negociando tanto diagnóstico como terapia social.

3. Si los sistemas sociales son autorreferenciales, ¿cómo influye un agente externo que intenta modificar condiciones y comportamientos? Hay que considerar que la orientación (guía reguladora) de los sistemas sociales (por ejemplo, la familia) tiene que tener en cuenta la autonomía (autopoiesis) de tales sistemas.

Estamos ante importantes líneas de investigación, cuya solución obliga necesariamente a la introducción de un nuevo planteamiento.

\subsection{El paradigma del convencionalismo (programación convencional)}

Respecto al paradigma anterior, que mantiene el carácter sistémico de la política social, conviene tener presentes aquellas corrientes de política social no-sistémica que caminan hacia similares resultados, pero que poseen unas premisas sociológicas totalmente diferentes.

Este paradigma interpreta el conocimiento sociológico en clave convencional o nominalista, derivado de las interacciones sociales entendidas a partir de aproximaciones cercanas al individualismo metodológico.

Nos encontramos ante planteamientos que, tradicionalmente, no han estado muy próximos a la política social, aunque existen ilustres excepciones como el caso de Max WEBER. En buena medida, esta separación se debe a la epistemología sociológica utilizada por este paradigma. Ésta no solamente niega que existan «leyes» en la/de la sociedad, también niega que la sociedad pueda tener cualquier carácter sistémico. Tiende a revelar el carácter libre, espontáneo, informal, en síntesis, autónomo de los singulares actores. El conocimiento sociológico contempla a estos actores y, en cierto sentido, es producido por ellos, incluso por sus singulares acciones de política social. No resulta arriesgado decir que estos planteamientos están presentes en las corrientes de la rational choice y en otras aproximaciones similares.

Teniendo en cuenta estas premisas, si bien es cierto que el paradigma convencionalista evita la downward conflation y la central conflation de los paradigmas precedentes, sin embargo, incurre en una upword conflation: se supone que las singulares acciones de política social, aquellas de los portadores (traeger) de intereses y cursos específicos de acción, producen situaciones sociológicamente relevantes de las que emerge el conocimiento en cuanto producto de estas acciones.

En el caso concreto de la familia, a ésta se le niega tanto el tener cualquier estructura a priori, como cualquier carácter sistémico que, sin embargo, en el segundo paradigma se mantenían (por ejemplo, en LuHManN). La familia es contemplada como relación entre individuos, especialmente a partir de motivaciones biológicas (la relación madre-niño) y culturales (variables y relativas, en función de preferencias, gustos y opciones de los actores). Lo social que existe en la familia es considerado como relación de recíproco afecto y utilidad entre individuos. Desde esta posición al paradigma economicista de la familia entendida como terreno de mercado (G. BECKER, 1991) existe solamente un paso.

En consecuencia, se niega la planificación social como acción normativa (desde arriba), como acción de un sistema, como acción de estructuras. Se la concibe como emergencia de un mercado, que puede asumir la forma de una especie de «mano invisible» 0 , simplemente, la de un orden que se produce «espontáneamente» mediante los intercambios individuales entre los actores ${ }^{11}$.

Las consecuencias son evidentes en el caso de la política social para la familia: una programación sólo puede entenderse como intervención en las necesidades de los individuos en relaciones individuales o interindividuales contingentes o casuales. No tiene ningún valor el conocimiento sociológico de la familia que se extrae de una interacción reflexiva entre investigación sociológica y política social. Estas premisas las podemos encon- 
trar en autores como VON MISES, VON HAYEK y el primer Jon ELSTER. Otros autores, como James Coleman, se enmarcan en este paradigma, aunque lo refuerzan (como hace el último Jon ELSTER en el «cemento de la sociedad») con elementos del resto de aproximaciones.

En cualquier caso, la planificación a la que aludimos es aquella de «mercado», entendida como categoría sociológica en sentido analítico: dejar actuar al mercado e intervenir ex-post, en parte para remediar sus carencias y fallos (estrategia generalmente considerada costosa y poco eficaz) y, sobre todo, para introducir otras reglas de mercado (de «mercado correcto», por ejemplo, bajo la forma de managed competition), que conduzcan a mejores interacciones desde el punto de vista de la equidad de los intercambios y de la satisfacción de los actores. El instrumento eje de la planificación es la privatización (como liberación) de las conductas y de las formas de resolver las necesidades sociales. Naturalmente, la privatización puede realizarse según numerosas y diversas modalidades (basta con consultar algunas revistas especializadas, como el Journal of Social Policy, para tener una amplia reseña).

\subsection{El paradigma relacional (la intervención de redes)}

$\mathrm{Ni}$ el paradigma del realismo ingenuo, que supone una estructura filogenética (con variaciones muy limitadas), ni el paradigma constructivista, que plantea una morfogénesis relativista de las relaciones sociales, ni el paradigma convencionalista, que niega una realidad sui generis a las relaciones sociales, pueden explicar que las instituciones sociales cambian pero permanecen, idénticas y diferenciadas, respecto a las formas precedentes. Por ejemplo, resulta verdaderamente difícil entender cómo la institución familiar puede cambiar de tal manera que, al mismo tiempo, es idéntica y diferente respecto a las formas precedentes. Éste es el sentido de la visión relacional.

En esta línea, puede ser útil tener presente que, desde la óptica de las políticas sociales, la familia se debe observar como transformable (al contrario que el planteamiento positivista) y, al mismo tiempo, se la debe considerar dotada de dinámicas propias, que no pueden ser reducidas a elementos comunicativos (al contrario que el planteamiento constructivista).

Ésta es la nueva instancia relacional, en la que se afirma y concibe a la familia en un sentido muy específico, ni bipoestático (según cierto materialismo) ni indeterminado (según un contingentismo puro). La familia es lo que se hace en las interacciones de vida cotidiana, allí donde estas interacciones no están determinadas a priori, ni son casuales, sino que tienen lugar mediante procesos morfogenéticos ${ }^{12}$. El eje del conocimiento sociológico es la relación social.

Cada realidad social se debe comprender como relación. En el caso de sistemas sociales como la familia, la relación tiene siempre su propia especificidad. Tiene su medio simbólico generalizado para los intercambios con el resto de sistemas. De esta forma, la familia tiene que ser observada como relación social sui generis.

En consecuencia, conocer la familia significa trazar nuevas diferencias. Significa comprenderla como construcción que no es ni una reiteración del pasado (de lo «ya dado» según las hermenéuticas de la tradición), ni una pura autoconstrucción (según automatismos internos libres de conexiones con el exterior). La familia emerge como un tipo de relación social que no puede se reducida a otra realidad.

De esta forma, la familia empieza a observarse como sistema social con específicas identidades, con límites variables, que no puede ser definido ni como mera respuesta a imperativos funcionales preestablecidos, ni según conceptos heterogéneos como del tipo «trayectoria de la vida». La familia debe redefinirse como sistema viviente dotado de un propio dinamismo relacional, basado en la plena reciprocidad, que, al mismo tiempo, constituye su medio simbólico generalizado de intercambio ${ }^{13}$.

Como posteriormente se verá, existe una profunda conexión entre lo anteriormente planteado y lo que acontece en el terreno de las políticas sociales. Observada desde la óptica de la política social, la familia, ya no aparece como algo puramente «natural». Aún más, también se encuentra desilusionado quien pensaba que podía condicionarla con otro tipo de «determinismos». La familia no es un sistema que se autoconstruye artificialmente, por inteligente que pueda ser. Tampoco puede ser asimilada bajo la figura del mercado. Los programas orientados hacia la consecución de cualquier objetivo de bienestar deben repensar la definición de familia que utilizan.

Ya no es válida ni la antigua definición normativa de familia, ni su disolución constructivista (la familia reducida a pura convivencia, a un haz de trayectorias individuales). Tampoco lo es la idea de familia como relación biológica entre individuos autorreferenciales. La familia debe descubrirse como exigencia relacional nómica en el bic et nunc, en su contexto situacional. Sin embargo, todo ello tiene lugar en un horizonte cultural, simbólico, en el que la familia permanece como un universal simbólico.

Quizás en este momento histórico, la recíproca observación y comunicación entre familia y políticas sociales resulta problemática. Todos sabemos que las políticas sociales, cuando deben elaborar programas de bienestar para las familias, especialmente para aquellas consideradas como marginales o desviadas, no saben que definición dar y como implicarla operativamente. Esta situación conlleva la necesidad de considerar a la familia como relación social que se genera: es una recíproca determinación, que consiste en su carácter de mediación simbólica y estructural. 
¿Qué conclusión se puede extraer? Para conocer a la familia como sistema relacional de límites variables, la sociología ba tenido que observarse a si misma, es decir, autoconcebirse y autorepresentarse, como relación social.

Para ser válida, la teoría que defiende que el conocimiento sociológico es observer-dependent debe ser reformulada: en contra del planteamiento de LUHMANN, finalmente se debe admitir que la dependencia del conocimiento sociológico del observador es una relación social, y no un mero proceso comunicativo o mental.

Si en algún momento el conocimiento sociológico cree ampliarse asumiendo paradigmas de otra naturaleza (biológica, cibernética, etc.), finalmente tiene que admitir que estas diferencias provocan «otra» diferencia no-sociológica.

Por ejemplo, con posterioridad, la familia siempre debe diferenciarse como relación social. Si la sociología quiere sobrevivir (es decir, distinguirse) debe regresar a sí misma, es decir, tiene que volver a comprender que trabaja con un meta-código propio (frame). Además, como ciencia relacional, tiene su identidad y operatividad en un meta-código relacional, en el que la política social juega el rol de un alter-ego ${ }^{14}$.

Similar a este paradigma es pensar la planificación social a partir de programas relacionales.

En los años noventa, las políticas sociales deberían replantearse reflexivamente, es decir, aplicándose a sí mismas sus propios efectos.

Para los que observan la situación con realismo crítico, las políticas sociales no pueden seguir ni programas condicionales, ni programas evolutivo-incrementales, ni sólo podemos liberalizar el terreno de lo social concebido como mercado. Si los programas condicionales no pueden ejecutarse por ser excesivamente normativos o normativos de forma inadecuada, y los programas oportunistas no ofrecen soluciones a los problemas, generalmente los programas de desregulación crean más problemas de los que solucionan.

Esta situación, generalizada en la vieja Europa de los años ochenta, puede ser descrita como una posición de inmovilismo. Las medidas de defensa del Estado (por ejemplo, la racionalización de los gastos) no proporcionarán soluciones significativas. En cualquier caso, está claro que el futuro de las políticas sociales no puede resolverse mediante una estrategia de tipo oportunista y contingente. ¿Qué se puede hacer?

En una situación como la actual, en Europa se plantean las siguientes condiciones:

- La formulación de las políticas sociales debe replantear los objetivos que orientan sus ejes no sólo en función de reducciones pragmáticas; también a la luz de valores dotados de sentido. Para éstos hay que buscar argumentos y justificaciones de consenso intersubjetivo y de relacionalidad sistémica entre los actores del Estado de Bienestar.

- La implementación de las políticas sociales ya no puede depender de uno o más actores privilegiados y ser perseguida linealmente (desde un centro hacia una periferia), debe buscar la colaboración y combinación entre los diferentes actores y sectores (público, privado de mercado y privado social) e inspirarse en intervenciones de redes.

- La evaluación del impacto no puede concebirse ni como análisis de tipo positivista (si X... entonces $Y$ ), ni como pura construcción social, ni como aprendizaje de un «orden mediante fluctuación», sino como un sistema de seguimiento abierto a posibilidades diferentes, controlable a escala limitada (micro-local), aunque se deben tener claros los enlaces con el nivel macro-societario.

Estas condiciones definen un nuevo planteamiento para las políticas sociales que denominamos relacional en cuanto que:

a) La observación, como intervención, es una relación que debe definir el propio objeto relacionalmente, es decir, a partir de un análisis de las relaciones entre el sistema que observa y el sistema que es observado; estamos ante conexiones simbólicas y estructurales que aluden a las relaciones internas de dichos sistemas.

b) La predisposición de los programas debe adoptar estrategias relacionales que se inscriben en un análisis y en un actuar de «redes» (intervenciones y estrategias de redes):

c) La interacción entre conocimiento e intervención debe ser capaz de captar reflexivamente al objeto-sujeto de la intervención.

De esta forma se explica por qué, en el caso concreto de la familia, las sociedades hodiernas tienen exigencias contradictorias que, al mismo tiempo, hacen temer y esperar a los sistemas públicos occidentales.

Estamos ante exigencias contradictorias y paradójicas porque las políticas sociales tienen que sostener a la familia. Sin embargo, no lo pueden hacer desde el marco de los viejos modelos normativos, todavía vigentes en la forma de concebir la intervención social. Aún más, son los únicos que el Estado social de tipo social-democrático (como compromiso entre democracia y mercado) acepta.

Nos encontramos ante dificultades que hacen emerger ciertos temores porque las políticas sociales viven de la solidaridad y se desgastan con ella. El desgaste (por ejemplo, como privatización) de la familia (tomada como unidad de referencia de los programas sociales) conlleva una inevitable debilidad de la política social.

Emergen esperanzas porque la aplicación reflexiva de tales resultados anima a la búsqueda de nuevas soluciones y nuevas integraciones sociales, más diferenciadas, en las intervenciones 
de bienestar. La familia debe ser más claramente diferenciada de lo que no es familia. Las redes informales de ayuda y asistencia deben crear otras formas de solidaridad social.

La sociología aplicada ha avanzado bastante cuando ha reconocido estas nuevas interacciones, alejándose de los determinismos teorizados por los planteamientos positivistas y constructivistas y de las espontáneas presuposiciones de los planteamientos individualistas. Sin embargo, actualmente se encuentra ante la dificultad de extraer de los nuevos acontecimientos algo que no sólo sea una teoría y una práctica de procesos improbables.

Aún sigue siendo problemática la observación de las relaciones y de las redes. Al elaborar un planteamiento relacional en sociología se debe tener en cuenta que esta disciplina no se asemeja a las teorías físicas cuánticas y postcuánticas, o las matemáticas de lo posible y del fuzzy sets. Sin embargo, éste parece que es el camino que hay que seguir.

La vía de salida ha sido trazada al ser conscientes de que la sociología encuentra obstáculos cuando se aleja de la política social. Puede superar los obstáculos mencionados si desarrolla un análisis relacional de las recíprocas determinaciones. Por ejemplo, tal análisis debería revelar que las políticas sociales están marcadas por un déficit de observación, y que la sociología tiene un déficit de normatividad. Todo aspecto teórico o práctico puede y debe ser contemplado «recíprocamente».

\section{La interacción}

conocimiento social/política social como «relación suprafuncional de reflexividad recíproca»

A pesar de que existen opiniones en sentido contrario, en las últimas dos décadas, las diversas formas de conocimiento y de intervención en la realidad social han caminado hacia un acoplamiento estructural ${ }^{15}$. Desde un acoplamiento marcado por la fusión desde arriba (desde el conocimiento) hacia abajo (microoperatividad), se ha ido pasando a un acoplamiento fusional central (en el sentido de una igualación horizontal entre sociología y política social, tal y como nos aparece en el constructivismo), y, con posterioridad, a un acoplamiento fusional desde abajo (subjetividad de los actores) hacia arriba (intervenciones programadas institucionalmente). Actualmente nos encontramos ante la necesidad de una redefinición. Ahora bien, para intuir en qué dirección se puede caminar hay que comprender cómo ha progresado la investigación sociológica aplicada y en qué medida se ha transformado en una función de reflexividad de las políticas sociales, y viceversa. Veamos las fases:

a) En una aproximación sociológica tradicional, la relación entre teoría y política social contiene escasa reflexividad en cuanto que está ligada a una concepción apriorista y condicional. El conocimiento de la realidad recorre caminos que nada tienen que ver con la política social como tal: de la teoría no se pueden extraer ni informaciones, ni normas que orienten a las praxis. También viceversa. Las políticas sociales ignoran sus contenidos teóricos: deben alejarse de la tentación de buscar premisas teóricas y del «hacer teoria».

Obviamente, presentan una formulación a priori tanto las presuposiciones que consideran a las políticas sociales como no útiles a la teoría, así como los planteamientos que defienden la no utilidad de la teoría para las praxis. Por ejemplo, negar de manera rotunda el ambiente metafísico de la acción social es, a su vez, una metafísica. Aún más, ésta es la explicación de la co-presencia de positivismos metafísicos y positivismos pragmáticos y empiristas.

De esta forma, retomando el ejemplo de la familia, se piensa que sigue lo que el Estado indica, aún dentro de los límites de acción, considerados «objetivos», de ambos. No resulta arriesgado decir que tal afirmación es falsa, tanto si se considera que la familia es positivamente funcional al Estado, como si se la considera disfuncional.

No es que este planteamiento, como algunos sostienen, no tenga presentes los posibles efectos intencionales de las acciones. La cuestión es que estos efectos se inscriben en una precomprensión del orden social de tipo naturalista o bien en una especie de «mano invisible» que sabe crear progreso, o incluso la representación de cualquier tipo de «evolución». El acoplamiento estructural del que se habla ha sido teorizado superficialmente. En la mayor parte de la ocasiones aparece como algo espontáneo. Aún más, siguen estando presentes patterns totalmente desvinculados de la efectiva interacción entre teoría y praxis social.

b) En un planteamiento constructivista, la relación entre teoría sociológica y política social incorpora reflexividad, pero lo hace de tal forma que prejuzga sus distancias y recíprocas diferenciaciones. Más o menos explícitamente, se piensa que son similares en cuanto forma de funcionar del sistema societario.

El acoplamiento estructural del que se habla está como «colapsado» en la Mind. El énfasis sobre la circularidad interactiva reprime las discontinuidades y las discrepancias entre los diferentes actores del sistema complejo de acoplamiento. Los procesos de simbolización son objeto de una lectura apática, en cuanto que uniformada por un código funcional. 
Esto no quiere decir que asistamos a una identificación entre familia y Estado. Pero se asume que el orden social sólo es lo pragmático de los actores en juego. No existe ningún orden, no hay lógica o código simbólico capaz de trascenderlos o trasladarlos a una autotrascendencia. Para estos actores sólo es válida la regla (material, vital) que cualquier sistema social, como sistema cerrado, puede hacer por y para sí mismo. Las interacciones (recíprocas comunicaciones) entre sistemas son tan sólo interferencias, estímulos indeterminados, empujes hacia la fluctuación de un sistema sobre otro.

En tal concepción, al final no existe intencionalidad ${ }^{16}$, la reflexividad (por ejemplo, entre familia y Estado) es presentada como deslizamiento de límites privados de cualquier dirección significativa. De esta forma, el constructivismo radical coincide con un neopositivismo en el que reina el primado del acontecimiento sobre la teoría. La teoría es fuerte en cuanto que expresa un cognitivismo que ignora y rechaza todo intento normativo no empírico.

c) En el paradigma convencional está más presente la intencionalidad de los actores, la subjetividad y la espontaneidad (libertad) inherente a sus intercambios, pero el resultado final no es muy diverso del que hemos encontrado en el anterior planteamiento. La teoría aparece como fruto de las preferencias de los actores. Buen ejemplo es el caso de la familia. Y las políticas sociales son respuestas a estas preferencias. Lo que hay de diferente en este planteamiento es el carácter más flexible, menos sistémico y, en consecuencia, una mayor «liberalización» de las políticas sociales. La planificación da un mayor espacio a los actores, a sus relaciones e iniciativas. El resultado es permitir a la teoría el estar menos vinculada con los prejuicios sistémicos, todavía muy fuertes en el constructivismo.

En cada uno de estos planteamientos se pueden detectar una serie de límites que, progresivamente, se hacen más evidentes. Tanto el conocimiento que se produce, como la correspondiente validez de la intervención social son insuficientes para afrontar los riesgos y las patologías sociales de una sociedad hipercompleja. Es necesario un cuarto tipo de acoplamiento entre conocimiento e intervención social.

d) Desde una concepción de tipo relacional, el acoplamiento es una relación social. La interacción entre conocimiento e intervención se conceptualiza y afronta alejándose tanto de la presunta separación, como de la pretendida fusión (entre estructura y actores, entre conocimiento e intervención). La primera presuposición de la relación es la misma relación, y sólo ella. Existe, con toda su magnitud, y no sólo en los aspectos comunicativo-informativos.

De esta forma, se contempla cómo la familia es un sujeto-en-relación con el Estado, que es otro sujeto-en-relación, aunque diferente («primario» el primero, de «carácter derivado» el segundo). Entre ellos ya no existe una «cadena», sino una red (network) relacional que los conecta. Por razones evolutivas (no evolucionistas), esta red se desarrolla a través de una continua diferenciación. Lo acontecido en las etapas intermedias de la red posee conexiones significativas con cuanto tiene lugar dentro de la familia y dentro del Estado.

El resultado es poder observar cómo, por ejemplo, el loose coupling de la familia es paralelo al loose coupling del Estado (mejor, del sistema político-administrativo). Además, la observación puede avanzar contemplando los acoplamientos que tienen lugar a lo largo del conjunto de las conexiones que los ligan a distancia. Sólo en este marco es posible ver cómo las políticas sociales actualmente se fragmentan y diferencian en sistemas intermedios que son unidades dotadas de una estructura de redes.

Allí donde la investigación sea válida, las aportaciones significativas de conocimiento sociológico procederán de la forma en que la política social recoja la pista de estas redes, que podrán observarse como una función reflexiva alargada de la política social ${ }^{17}$. Viceversa, la intervención social se beneficiará en cuanto que se convertirá en una función reflexiva del conocimiento sociológico perseguida con instrumentos propios.

Una vez más, lo acontecido en el campo de la familia puede ser útil. Dejando al margen las ideologías que sostienen a los Estados hodiernos, la investigación sociológica aplicada a la familia ha producido un determinado tipo de conocimiento que ha seguido la dirección establecida por la política social. Esto no impide que el conocimiento de la familia pueda dirigirse hacia otras direcciones. Por ejemplo, en las relaciones con la literatura, con la religión, con el arte, así como con el Derecho o la economía. Ahora bien, en estas páginas nos interesan las relaciones con la política social, en sus aspectos de sociología aplicada.

Los interrogantes: «¿ंqué es la familia?», «ंpuede cambiarse mediante la política social?», «si es así, ces legítimo?» nos trasladan a los acoplamientos relacionales implicados. Más concretamente, nos podemos encontrar ante problemas tales como: si la caída de la natalidad puede o debe conllevar un replanteamiento de lo que es la familia en la actualidad y en el futuro; si y cómo la fragmentación de la familia se conecta al desarrollo y a la crisis del Estado de Bienestar; si se pueden o se deben reconocer jurídicamente, y con qué modalidades, a las uniones de hecho, eliminando las distinciones con la familia legal; si se puede contemplar la familia como una simple variable de trayectorias de vidas individuales; etc.

Cada uno de estos interrogantes lanza a la sociología, como forma de conocer y saber, un problema similar: ¿cuál es la sustancia social específica de la familia?, ¿cuál es su contenido sociológico?

La respuesta a estos interrogantes se ha buscado en la construcción de la realidad social observada (a partir de premisas 
«naturalistas»). Cuando la sociedad se ha hecho estructuralmente (normativamente) relacional, este planteamiento ya no es suficiente para entender y actuar. En la sociología necesariamente se introduce la política social como conjunto de las acciones sistemáticas sobre la familia.

Ofrecer respuestas a las anteriores preguntas cognitivas implica otro interrogante preliminar: teniendo presentes los ejes centrales de la política social, cqué lugar ocupa en la sociología la búsqueda de respuestas?

Si la respuesta es: «un lugar secundario», en cuanto que teoría y praxis están totalmente desligadas entre sí (o bien: se considera que la conexión es «espontánea», o está en los «hechos subjetivos»), nos encontramos ante el primero o el tercero de los planteamientos. Si la respuesta es: «son la misma cosa», estaríamos ante el segundo planteamiento. Si la respuesta es: «se debe elaborar una distinción directriz de su relación», nos encontramos ante el cuarto planteamiento. En sociología, a la familia se la conoce por cómo es activada en y mediante la política social (como se la conoce, desde otros puntos de vista, en y mediante la economía, la religión, el arte, etc.), y no «en sí misma».

Todas y cada una de esas premisas son de especial interés para el análisis de las relaciones de mundo vital y las instituciones del Estado social. Su interacción transfiere conocimiento de las praxis de bienestar a la teoría, así como la teoría de los mundos vitales se encarga de transferir normatividad a las políticas sociales. Otra cuestión es que se puedan adaptar la una a la otra.

Las sociedades del Tercer Milenio buscan un sistema relacional apropiado entre el mundo de la vida cotidiana y el Estado. Un sistema interactivo que sea capaz de elaborar conocimiento y evaluación, y que persiga políticas sociales coherentes.

Puede ser útil esbozar un ejemplo que aluda a la frontera entre conocimiento sociológico y política social sobre la familia en la actualidad. Si el análisis de mundos vitales nos enseña que la familia sobrevive como grupo e institución que desempeña importantes funciones sociales, ¿̇por qué no se considera (en la teoría) que el conjunto de las familias es un subsistema societario (de la misma forma en que se plantea el sistema económico, el sistema administrativo o el sistema de los mass-media como subsistemas de la sociedad)? Buena parte de las teorías sociológicas rechazan este reconocimiento cognitivo. Este rechazo nace del no haber captado nada o casi nada de las políticas sociales.

Los planteamientos tradicionales no niegan que la familia sea un subsistema societario, pero consideran problemática esta afirmación. La consecuencia es que las políticas sociales ignoran las implicaciones de la teoría (de la familia como subsistema societario). Por el contrario, los planteamientos constructivistas y convencionalistas explícitamente niegan la anterior teoría. Las causas son complejas. Sin embargo, trasladan al déficit de capacidad de simbolización que está presente tanto en el constructivismo sistémico como en el convencionalismo. Ambos generan dramáticos problemas de definición de los límites de la acción estatal hacia las esferas de la vida cotidiana. $\mathrm{Si}$, como ocurre en el planteamiento constructivista, la familia no posee funciones propias (ni un medio simbólico generalizado de intercambio), ¿qué garantías existen, desde el punto de vista de las políticas sociales, respecto a los límites de intromisión de los otros subsistemas (el mercado, el Estado, etc.) en la familia? ¿Bastará con poner de manifiesto que la familia está dotada de una autopoiesis comunicativa propia que le permite garantizar políticas sociales que no colonizan y manipulan? El planteamiento convencionalista no puede decir nada al respecto, tan sólo confiar en el carácter «privado» de las relaciones familiares y de mundo vital.

Cada una de estas perspectivas resalta negativamente el modo de entender la relación entre conocimiento y política social. La autonomía comunicativa de las esferas sociales (como la familia) es un punto firme, es una cognición necesaria, pero no es suficiente para observar y describir adecuadamente estas esferas (como la familia hodierna) ${ }^{18}$. Hay que recurrir a un nuevo paradigma relacional que reconsidere lo descubierto en nuevos niveles, más diferenciados pero también reintegrados, de conocimiento e intervención social.

Este paradigma emerge del desarrollo de aquellos servicios de care que contemplan a las familias implicadas como sujetos de servicio en formas asociativas, cooperativas, de mutualidad, de empresa social, de voluntariado, en resumen, de privado social. Aquí es donde se manifiesta actualmente la innovación social más significativa.

Estas innovaciones han nacido y se han difundido como fenómeno de modernización cuando las familias han reflexionado sobre sí mismas como comunidad de discurso. Es decir, cuando, como portadoras de políticas sociales, han sabido producir un conocimiento nuevo (por ejemplo, como teoría de las redes informales) y la teoría posteriormente se ha desarrollado de forma reflexiva, interaccionando con las políticas sociales.

La intersección entre redes informales y formales es un tema complejo. Aún más, las relaciones entre público y privado, las fusiones y las diferenciaciones, los conflictos y las colaboraciones constituyen un problema que se desplaza desde la modernidad a la postmodernidad. El aspecto a resaltar es que, en la actualidad, tales intersecciones son la expresión de una nueva y creciente reflexividad entre teoría sociológica y política social. De esta reflexividad se pueden extraer consecuencias cognitivas, éticas y operativas que modifican la configuración del Estado social. Nos encontramos ante el tema de nuevas solidaridades que se entrelazan con nuevas libertades. 
Tanto en la praxis como en la teoría, el proceso interactivo avanza mediante pruebas-y-errores, con las correspondientes dificultades, incoherencias y contradicciones. Como tal, el sistema relacional ni ha sido desarrollado teóricamente, ni ha sido puesto en práctica. A pesar de ello, el análisis sociológico puede desarrollar posteriores observaciones que contemplan a la familia como algo diverso, más «sutil» y profundo, no como algo dado o como una construcción social, sino como una realidad dinámica y sui generis que debe encontrar desarrollos vitales progresivamente más diferenciados.

Esto debería ayudar a comprender que la familia no se puede utilizar como un «operador» según programas definidos de forma externa a sus redes relacionales. Porque, al final, éste es el sentido de la afirmación de que el conjunto de las familias es un subsistema societario. Y éste es también el espacio de la investigación aplicada, para un conocimiento finalizado en la intervención social (investigación-acción, investigación-intervención, etc.).

Como hipótesis de trabajo, una investigación orientada en esta dirección podría mostrar cómo el concepto de «trayectoria de vida» no puede sustituir al concepto de familia. Por otra parte, cómo la continua oscilación entre selectividad y universalismo en las prestaciones de bienestar reclama algo que, en la distinción entre planteamientos individualistas y planteamientos relacionales, no ha sido tenido en cuenta ni por sociólogos y ni por policy-maker.

En el amplio panorama de la diferenciación social:

- El observador deberá reflexionar con mayor profundidad sobre el punto de observación más adecuado para la acción.

- Siempre teniendo presente que la acción influirá en la observación (teoría).

- Pero, en este proceso, no todo se autoconstruye o se auto-observa: la realidad permanece como sustrato que no depende ni de la observación, ni de la acción.

Para ser gestionada adecuadamente, esta fenomenología requiere, además de una teoría de los sistemas orgánicos, psíquicos y sociales (comunicativos), una teoría del sujeto y una teoría de la cultura. Esto es cuanto revela la sociología relacional. El caso de la familia tan sólo es un ejemplo.

El conocimiento sociológico no puede quedar reducido a mera praxis y viceversa. Por así decir, en el centro se ubica la relación social con sus exigencias de sentido, como subjetividad (intencionalidad) y significado (simbolización). Ahora bien, conviene subrayar que la relación no es simplemente interacción simultánea entre términos: es «fenómeno» emergente, es decir, está en otro nivel, resaltado por el tiempo, según procesos de condicionamiento estructural de interacciones que continuamente re-elaboran el sentido de las relaciones sociales, su configuración, produciendo un nuevo contexto desde el que se inicia un nuevo proceso de emergencia social.
El modelo tradicional (positivista) apela a una relacionalidad normativa limitada y eficaz en determinados casos. El modelo constructivista es relacionalista (nos traslada a una relacionalidad circular). El modelo convencional carece de relacionalidad social en cuanto que la reduce a proyección de individualidad. Por tanto, es necesario comprender en qué consiste la relacionalidad de lo social.

Tal y como sostienen REIN y PEATTIE (1981), las conexiones entre aspectos procedentes de dos puntos de vista (sociología y política social) jamás han sido estructurados según las exigencias de la sociedad en que vivimos. El motivo es bien sencillo: entre teoría sociológica y praxis político-administrativa está la relación social con su propio dinamismo.

La política social necesita una teoría. La teoría necesita una política social. Sólo la reflexividad recíprocamente diferenciada puede ayudar a la teoría a ser un conocimiento adecuado al objeto; igual para las políticas sociales, es decir, normatividad adecuada a los sujetos en los que se interviene. El secreto es no perder su intrínseca relacionalidad.

Llegados a este punto se debería presentar un elenco de ejemplos aplicativos: las políticas de empleo, de infancia, sanitarias (por ejemplo, de primary bealth care y de «salud para todos»), las políticas de linkage entre redes primarias de apoyo y servicios formales, políticas de consultorios familiares, de apoyo al asociacionismo, de voluntariado y de cooperación familiar, de community care, etc.

En cada uno de estos campos emergen nuevas interacciones entre conocimiento e intervención social. Dichas interacciones deberían afrontarse y gestionarse como sistemas relacionales de observación-diagnóstico-guia.

\section{La programación social como relación entre conocimiento e intervención: los sistemas de observación-diagnóstico- guía relacional (ODG)}

¿Qué significa que el sistema interactivo entre conocimiento e intervención social debería ser una relación de captación reflexiva adecuada? En primer lugar, significa que la diferenciación interna al conocimiento depende de sus relaciones con la inter- 
vención social y viceversa, es decir, que sociología y política social deben interactuar relacionalmente si quieren adecuarse al objeto. Esta interacción se desarrolla en el tiempo (son fases, acciones y retro-acciones que tienen lugar en etapas sucesivas) y debe estar «guiada».

El sistema relacional es un sistema de captación cuando es capaz de diferenciarse y reintegrarse continuamente a partir de sus resultados. Debe aprender de las consecuencias sin caer en el puro consecuencialismo. Para hacerlo, dicho sistema debe estar dotado de un adecuado código cognitivo y de evaluación. A su vez, esto implica un meta-código. La fenomenología nos ha enseñado que toda descripción también es una evaluación, y que el discurso sobre el código simbólico siempre nos traslada a un meta-código.

Puede ser útil terminar estas aportaciones aclarando tal perspectiva, que conlleva la necesidad de regular y resolver los problemas sociales mediante la construcción de sistemas de observación-diagnóstico-guía relacional (que llamaremos brevemente sistemas ODG).

La construcción de estos sistemas tiene que evitar la fusión entre estructuras y actores en sus diversas modalidades. Conviene recordarlas:

- Fusión hacia abajo. Cuando se considera que la modificación de las estructuras y de los contextos institucionales implica la adaptación de los individuos y de las familias.

- Fusión hacia arriba. Cuando se piensa que los comportamientos de los individuos y de las familias pueden dar indicaciones inmediatas, espontáneas, sobre las políticas sociales, es decir, se establece como premisa que los actores sociales son portadores de un orden que, ipso facto, indica las modificaciones necesarias de las estructuras y de los contextos institucionales, que simplemente deberían adaptarse a los gustos y preferencias subjetivas.

- Fusión central. Consiste en ubicar en interacción horizontal, atemporal, los términos de la relación, suponiendo que la planificación social consiste en el trabajo de sistemas autopoiéticos autorreferenciales.

Más bien se trata de asumir un modelo de planificación morfogenética que puede definirse como gestión de relaciones sociales ${ }^{19}$.

Los sistemas ODG son respuestas a situaciones de crisis que utilizan diversos instrumentos según un modelo relacional «guiado» desde una óptica de redes. Para los especialistas se podría decir que los sistemas ODG son sistemas del tipo relación-ÁGIL ${ }^{20}$. En ellos, la L (que es el value-pattern de las redes) guía al sistema societario utilizando diversos paradigmas de politica social como particulares instrumentos para intervenciones concretas en áreas específicas de acciones:
- (A) La planificación convencional, de mercado, es aquella que actúa mediante mecanismos espontáneos de intercambio, y se adapta a aquellas áreas de intervención en las que la política social debe dejar espacio a gustos, preferencias y opciones de los singulares actores (reglas e instrumentos de privatización).

- (G) La planificación constructivista es aquella que contempla la eficacia (objetivo) y puede adaptarse a situaciones en las que se requieren intervenciones «por objetivos» (policies by objective).

- (I) La planificación normativa o condicional se activa desde una posición de mando, que debe asegurar solidaridad y coordinación, y que es propia de aquellas esferas que trabajan con los mecanismos de integración del sistema societario (por ejemplo, el sistema fiscal).

- (L) La planificación relacional está más próxima a los mundos vitales, a las asociaciones, al mundo de la community care, alli donde se trata de trabajar sobre relaciones, con relaciones, mediante relaciones sociales, ubicando en sinergía formal e informal todo tipo de actores sociales. Esta filosofía puede ser adoptada, como medium simbólico, en otras esferas y debe guiar - relacionalmente - a las diversas modalidades de planificación (normativas, constructivistas, mercantiles), aunque estas últimas aporten input esenciales y tengan que ser tenidas en cuenta por la planificación relacional (en la L de ÁGIL).

En este sentido, los sistemas ODG son una forma de programar que controla los diversos componentes del sistema (las políticas por objetivos, de privatización y de intervención de redes) de acuerdo con un principio de subsidiariedad en el que todo actor tiene su esfera de acciones sociales y debe estar en condiciones activar su propio rol.

Puede resultar interesante presentar el argumento racional que se esconde detrás de esta visión de las relaciones entre sociología y planificación social.

Cualquier política social es una intervención en un estado de cosas que es considerado insatisfactorio. Aún más, toda intervención social presupone una definición de la situación que contiene una evaluación. Por tanto, el primer problema sociológico no es si la sociología tiene que ser —en cuanto ciencianeutral, sino que está constituida por su capacidad de distinción entre conocimiento y evaluación.

El segundo problema a afrontar en las intervenciones sociales es el siguiente: la sociología contemporánea es consciente de que los sistemas destinatarios de las intervenciones (individuos, familias, grupos sociales), en cuanto sistemas complejos, se comportan de forma contraintuitiva; no se sabe donde puede finalizar la intervención (la interacción que se efectúa con los llamados destinatarios o usuarios). Estamos ante un problema que está siempre presente en las profesiones sociales, psicológicas y sanitarias, al mismo tiempo que constituye la pesadilla 
de los policy makers, ya que los efectos inesperados son típicos de las sociedades complejas.

Otras dificultades emergen del siguiente hecho: una intervención social eficaz presupone: (i) la posibilidad de una comunicación significativa entre operador y destinatario, y (ii) la posibilidad de modificar recursos y contextos por ambos. Se trata de condiciones cada vez más difíciles de realizar. En concreto, el cognitivismo sistémico conlleva la dificultad de que una comunicación intencional pueda aflorar alli donde se tiene que trabajar con «sistemas» que no sirven para tratar «intenciones».

En consecuencia, una intervención eficaz debe satisfacer muchas condiciones. Concretamente, presupone la posibilidad de una comunicación significativa para quien la recibe. Sin embargo, salvo casos excepcionales, ni las políticas sociales directivas (condicionales), ni las paradójicas (que consideran positivamente los síntomas, prescripciones invariables, etc.) han demostrado una capacidad de comunicación significativa. Las políticas de des-regulación, o que apelan a un orden espontáneo, han sido un fracaso o producen efectos perversos a causa de los procesos de estratificación y exclusión que se derivan (como en el caso de las nuevas pobrezas extremas). Esto no impide que, en determinadas situaciones, una de estas modalidades pueden ser aplicada con éxito.

Ante esta serie de circunstancias, ¿qué se puede hacer? Las teorías cognitivas más recientes muestran que las mejores soluciones proceden de las políticas evolutivo-incrementales. Sin embargo, también han puesto de manifiesto nuevas dificultades. En concreto aquellas derivadas del siguiente hecho: el impacto de la comunicación intencional presente en los programas de intervención social depende de los autónomos procesos de transformación de las señales (información, comprensión, aceptación) por parte del target-system. Este último es el que define los criterios de posible intervención, ya que sólo el sistema destinatario puede transformar las señales externas de estímulo en operaciones internamente relevantes. El resultado ha sido que los programas de bienestar se han bloqueado ante la incapacidad de los sujetos destinatarios para asumir la comunicación intencional (los programas sociales).

La conclusión que se debería extraer es que, desde su formulación, las políticas sociales requieren estructuralmente una implicación de los actores-sujetos. Sin embargo, a excepción de algunas experiencias (por ejemplo, en la action research), la formulación de los programas cede ante la presión de las situaciones: en estos casos resulta extremadamente difícil implicar a los sujetos destinatarios (especialmente si se encuentran ante una situación de necesidad, de falta de concienciación, etc...), en otros prevalecen intereses externos (de los lobbies, partidos, de la lógica política con sus intercambios, etc...). Dicho en otros términos, la política social sigue manteniendo interacciones distorsionadas con la teoría sociológica.
En este campo, antes que nada, la investigación finalizada debería aclarar estas distorsiones. Pero, al hacerlo, también tendría que tener en cuenta y dar una solución a las características específicas del sistema en el que se quiere actuar.

En lo referente a las intervenciones de bienestar, la política social debería ser desarrollada como sistema ODG capaz de producir ${ }^{21}$ :

- Una observación que sea consciente de las paradojas de los sistemas de observación y apta para tratarlos.

- Un diagnóstico que sea una descripción adecuada de los problemas sociales en los que se quiere intervenir.

- Un programa de intervención que se configure como guía relacional, hecho éste que implica el tener presente en la implementación y en la evaluación de los impactos los elementos constitutivos que siguen la secuencia temporal del programa (planificación social).

\section{Veamos detalladamente cada uno de estos puntos:}

1. La observación. Generalmente, un programa de bienestar parte de la observación de un estado de necesidad sin ser capaz de conceptualizar y advertir la propia autorreferencialidad. Dicho en otros términos, se inicia con la definición de las necesidades sociales, pero éstas se observan desde un sistema que es externo a lo observado y, en la mayor parte de las ocasiones, se debe reconocer que no se poseen instrumentos de conocimiento de las «necesidades efectivas» de las personas en las que se debe actuar.

En sociología, recientemente se ha puesto de manifiesto que la observación tiene un carácter paradójico en cuanto expresa (describe) el sistema que observa y no la realidad observada. Se dice que el referente primario de la observación es el sistema que observa. La observación es una autorreferencia.

Desde el punto de vista práctico, en las relaciones entre operador social y usuario de los servicios de asistencia, los actores interactúan en el terreno de la no-transparencia mutua. Toda mente es opaca por/a sí misma.

Ahora bien, esta teoría, que pretende afrontar las dificultades de compresión de las necesidades sociales, es excesivamente reductiva. Nace en el ámbito de las ciencias biofísicas y, al ser transplantada al ámbito de lo social, olvida los rasgos distintivos de las relaciones en este campo de la realidad. Ciertamente, la mente no es transparente, pero, por este motivo, existe la cultura como conjunto de referentes simbólicos que nos aproximan a las representaciones necesarias para comprendernos en la comunicación. Por otra parte, aunque es correcto considerar un procedimiento cognitivo que se inicia con la problematización de la realidad, sin embargo, es erróneo cuando se eleva el método a conocimiento. Desde el punto de vista epistemológico, asumir este punto de vista teórico significa ubicar la «sospecha» como primera presuposición general de la 
teoria, difícilmente conciliable con las exigencias del realismo crítico que son propias del análisis y de la práctica de los sistemas ODG.

La teoría autorreferencial nos ha liberado de las premisas del realismo ingenuo y del voluntarismo ideológico. Nos ha enseñado que se puede ver aquello que no se ve cuando somos conscientes de que no se ve. Sólo si ego y alter son conscientes de su intra-sistémica y mutua no-transparencia, la interacción puede pasar de ser una «caja negra» a una interacción «clara», capaz de captar reflexivamente los sistemas en interacción.

Por tanto, la observación de las necesidades sociales no es imposible o improbable, más bien habría que decir que no puede prescindir de la preliminar interacción entre el sistema que interviene y el sujeto destinatario.

2. El diagnóstico. Una intervención concreta presupone una descripción valorativa de la condición en la que se quiere intervenir. Dicha descripción se realiza en términos de distinciones entre patología y normalidad (de forma más general, entre estado satisfecho e insatisfecho), es decir, un diagnóstico. Éste es un caso especial de descripción que condensa la observación general de una situación a través de la focalización de la diferencia entre situación o comportamiento normal (o satisfecho) y patológico (o insatisfecho).

Ahora bien, describir algo significa observarlo (distinguirlo) y trasladar dicha observación a una forma semántica. Ya hemos hablado anteriormente de la observación y de sus premisas. Por lo que respecta al transplante semántico, decir que se trata de construcciones sociales que se apoyan en la comunicación mediante el lenguaje, pero éste no es simplemente una serie de signos y de mensajes. También es una elaboración de sentido (como significado e intencionalidad) y el sentido es una relación a la relación. Éste es el límite de los sistemas expertos y de las inteligencias artificiales. Aunque puedan ofrecer un apoyo cognitivo, al elaborar un «diagnóstico» no pueden sustituir este relacionamiento que solamente es humano.

Las teorías cognitivas han revelado que para que una descripción sea adecuada es necesario:

a) Que la reducción realizada por el observador a través de su sistema de referencia sea conceptualizada mediante el uso de otros puntos de vista (hecho que puede realizarse ubicándose en otros puntos de vista).

b) Que el operador sea consciente de los límites de sus descripciones para conceptualizar el problema social.

c) Que se recurra a una revisión del diagnóstico, por lo menos en los casos de mayor incerteza; la revisión debe entenderse como el juicio de una tercera parte (individual o de grupo) sobre el diagnóstico diferencial entre sistema que observa y sistema observado.
El sistema interactivo entre operador social y sistema-objeto de la intervención (como entre formulación de un programa y su implementación) se convierte en una «caja transparente» cuando se pasa de un juego de prueba-y-errores a una interacción lingüística e instructiva.

Operativamente son necesarias «muchas descripciones de trabajo»: tales descripciones sirven como modelos de simulación que serán válidos mientras describan bien el comportamiento de alter o el desarrollo de una situación. Obviamente esto implica aceptar y tratar las negaciones y controversias que pueden emerger de tales comportamientos o evoluciones.

Por todo ello, un diagnóstico no arbitrario, en condiciones de complejidad, implica una cierta suma de controversias. Lo que confirma que los sujetos destinatarios de la intervención no pueden ser diagnosticados desde un sistema experto externo que pretenda pasar por encima de sus cabezas.

En conclusión, el diagnóstico es algo más que una observación-descripción-comunicación lingüística: es una relación social, y como tal debe ser pensada y activada.

Es inevitable aceptar cierta negociación entre diagnósticos diferenciales. El arte de la intervención se apoya en transformar el disentir y el carácter emotivo contingente de las descripciones en un proceso capaz de aprendizaje no sólo cognitivo, sino también afectivo y simbólico-moral.

3. La intervención como guia relacional. Ni las intervenciones directivas (programas autoritarios, condicionales, «racionales»), ni las paradóiicas (rituales, de connotación positiva de los síntomas o de liberalización del comportamiento desviado) han sido apropiadas para los sistemas sociales complejos hodiernos, los cuales tienen como rasgo central comportarse contra-intuitivamente.

Más adecuados pueden ser los programas relacionales. Éstos son capaces de combinar procesos de aprendizaje conjuntamente cognitivos y normativos, con una configuración del sistema interactivo que permita auto-regularse a los actores que individuan fines comunes que cada uno persigue autónomamente en el propio ámbito de acción. Se trata de un proceso de diferenciación e integración reflexiva por parte de subsistemas sociales autogestionados que actúan en networks de elevada complejidad.

La «guía relacional» no es una forma de concertación ${ }^{22}$. La concertación no es el modelo apropiado de «guía relacional». Quien piensa en la concertación como filosofía de planificación tiene en la cabeza un modelo estructuralista y mecanicista de los sistemas ODG, el cual pretende orientar a los actores mediante el control del contexto (se habla de una intervención indirecta porque sostiene que es posible condicionar las condiciones contextuales). 
Puede ser útil, a fin de acceder a una diferente concepción de los programas relacionales, exponer y criticar este modelo.

WLLKE afirma que la guía relacional tiene que entenderse como el arte de intervenir en un sistema complejo, intervención que debería estimular reacciones que presentan modalidades estables y coherentes (patterned) dentro de un cambio estructural controlado del sistema (el target-system en su situación).

El punto de partida viene dado por una serie de aspectos, elaborados por la teoría de los sistemas autorreferenciales, referentes a las características del «sistema enfermo» o patológico en el que se quiere o debe intervenir:

- El primer obstáculo para la modificación del sistema es el mismo sistema. No en vano, su «mente» rechaza cambiar el propio comportamiento patológico o problemático. Por tanto, es insensible a las intervenciones encaminadas a modificarlo desde el exterior.

- Tal sistema tendencialmente reclama la atención del operador social (policy maker). Sin embargo, tal reclamo se hace a partir de aspectos que no son centrales en la emergencia de la patología. Intervenir en ellos conlleva destinar al fracaso de forma anticipada la intervención.

- El sistema posee muy pocos «puntos de influencia» (sensitive spots). Estamos ante peculiares criterios selectivos desde los que solamente el sistema es capaz de desprender informaciones relevantes para el mismo.

- El sistema social tiende a resistirse al cambio porque se rige por un equilibrio «duro» que deriva de factores contradictorios que lo «bloquean».

La guía relacional, continúa WiLLKE, es aquella que, tras tener presentes tales características, actúa respetando la integridad (autonomía) del sistema destinatario de la intervención. $\mathrm{Al}$ mismo tiempo, promueve un cambio estructural organizado del contexto que facilita la aportación de nuevas informaciones por parte del sistema. La intervención, llamada contextual, llega a modificar el sistema apelando a sus operaciones internas, mediante la inserción en un contexto que envía determinadas informaciones y no otras, encaminadas hacia sus sensitive spots.

Desde esta óptica, las políticas sociales actúan de forma indirecta ya que lo único que pueden hacer es condicionar los parámetros contextuales. WLLKE insiste en que, si la intervención trata de imponer, implantar o transplantar significados, valores u objetivos desde el exterior, el sistema reaccionará con acciones inmunitarias de rechazo y con el colapso de la autonomía de las personas y/o del sistema implicado. Por tanto, el frame de WILLKE es estructuralista y conductual. No en vano, se considera que los sujetos son moldeables desde el exterior mediante modificaciones de las estructuras de oportunidades y de las reglas del juego.

Sin embargo, constituye un gran problema basar los programas de guía relacional en un frame de este tipo. La relación social no es una transacción sistema/ambiente que sólo pueda modificar las reglas operativas de un sistema mediante mensajes externos que contienen informaciones cruciales para tales reglas (autorreferenciales). Efectivamente, en la intervención social se debe tener presente y utilizar este tipo de frame, pero no es suficiente: también son de gran utilidad las informaciones que aluden al interior de los sistemas implicados, observado y que observa (sujetos), y a su ambiente (cultura). Es necesario otorgar una mayor subjetividad a la sociedad (P. Donati, G. RossI, 1995).

Tal y como plantea WLLKE, la guidance es un proceso con éxito cuando consigue establecer las apropiadas conexiones entre el target system y la intervención exterior. También hay que tener presente que la «guía» es una gramática de reglas de transformación, un coupling (más o menos estricto), para las operaciones de transferencia de informaciones que modifican una definición de la situación y de las reglas para tratarla. Ahora bien, hay algo más. Si solamente fuera esto, la relación entre sistema y ambiente sería lo único que la sociología y la política social podrían concebir: nos encontraríamos ante el más puro relacionismo. Que, en realidad, impregna toda la obra de WILLKE, fiel seguidor de LUHMANN.

Quizás fuera necesario plantearse los siguientes interrogantes: ¿lo que acontece en el interior de los sistemas implicados es irrelevante tanto para la sociología como para la política social?, ¿también lo es el contexto cultural de los valores y de los significados del ambiente social, aquellos que dan sentido al lenguaje utilizado por la observación y el diagnóstico?

En cuanto que dan contenido a las relaciones de los sujetos de la sociedad, una teoría relacional tiene que mantener el vigor y la importancia del sujeto (personalidad, conciencia) y de la cultura (el mundo de la significación). Si no fuera así, ¿cómo se podría concebir la autonomía del sistema destinatario de la intervención y el carácter sensato de las selecciones activadas? Tanto personalidad como cultura son sistemas relativamente autónomos, pero se encuentran interpenetrados y son interdependientes con el sistema social (de la comunicación).

Si es verdad que los cambios sólo pueden activarse como cambios auto-realizados, y las intervenciones de bienestar sólo son eficaces cuando facilitan, inician o promueven procesos de auto-transformación del target-system; entonces son necesarias una teoría y una práctica adecuada al sujeto (en caso contrario nos encontraríamos ante su alienación), y una teoría y una práctica de la cultura (si no se corre el riesgo de provocar anomia). De esta forma es como debe concebirse un paradigma plenamente relacional.

La indicación fundamental de la «guía relacional» es la siguiente: la única forma para cambiar eficazmente sistemas vivientes complejos es iniciar un proceso de auto-transformación. En el caso de la política familiar esto implica el desarrollo 
de modelos de intervención orientados a reforzar (como empowerment) las familias, antes que insistir en las compensaciones de las deficiencias (el llamado deficit-model, que interviene ex post con una asistencia autorreferencial).

El diseño complejo que se deriva consiste en establecer una lógica de intervención basada en una red de actores autónomos, capaces de gestionar su intrínseca (estructural) autorreferencialidad relacionalmente. Éstos son los sistemas ODG, que trabajan a partir de un principio de subsidiariedad en el que el Estado, el Mercado, el Tercer Sector y las familias son los actores autónomos fundamentales.

\section{Los sistemas ODG emergen cuando se asume que:}

1. Los modelos de planificación (planning) condicional son problemáticos y no adecuados en cuanto que no respetan la autonomía de los actores en juego y se basan en un orden jerárquico que los sistemas complejos no toleran, aún más, anulan.

2. Los modelos evolutivo-incrementales también son problemáticos porque, al dejar que las cosas avancen mediante ajustes estocásticos, a corto plazo, localmente, en circunstancias dadas, en síntesis, sin dirección, incurren en la anomia; y no son adecuados ya que revelan crecientes efectos perversos.

3. Los modelos de desregulación y de utilización de instrumentos de mercado, o, en general, de privatización, pueden tener algunas ventajas a corto plazo y a escala limitada. Sin embargo, para ser eficaces, deben actuar en el marco de reglas complejas del sistema societario, reglas que deben ser dadas, como su prestación especifica, por otros sistemas no mercantiles (Estado y Tercer Sector).

4. Los modelos relacionales son aquellos que son capaces de elaborar estrategias que respetan la integridad de los sin- gulares individuos (subsistemas autónomos), al mismo tiempo que promueven un cambio estructural organizado mediante la formación de contextos culturales en los que un mínimo de orientaciones comunes de valores permite la autogestión de los subsistemas, dentro de los límites de su autonomía. En principio, parecen estar más capacitados para evitar las carencias que aparecían en los modelos precedentes. Ahora bien, para desarrollarlos, es necesaria una teoría general de la sociedad como relación morfogenética.

Cada uno de estos métodos de planificación puede aplicarse en su propio ámbito (los cuatros sectores que analíticamente comprende ÁGIL). Sin embargo, en cuanto que es el menos reductivo en el plano sociológico, el último modelo se ubica en una posición sui generis: tiene una función específica (las intervenciones de redes) y una función general, que consiste en producir y mantener el contexto de reciprocidad relacional. Dicho contexto es el fundamento del resto de modelos o métodos de planificación e intervención. Aún más, en él se apoya el sentido de una planificación social en términos de sistema -ODG.

Para concluir, el objetivo de la investigación sociológica en relación a las políticas sociales consiste en producir un nuevo enlace estructural y cultural de tipo morfogenético. Dicho enlace debe responder al problema de un conocimiento eficaz entendido como relación suprafuncional de reflexividad entre conocimiento e intervención social. En cualquier caso, para que las interacciones entre política social y sociología puedan dar vida a un sistema instructivo, es necesario que sus relaciones rechacen los postulados del positivismo, del constructivismo y del convencionalismo. Sería un primer paso para abrirse a una perspectiva sociológica que tenga presente la subjetividad de la sociedad.

\footnotetext{
* Universidad de Granada. Este artículo forma parte de los resultados de un proyecto financiado por el Ministerio de Ciencia y Tecnologia, PB98-1633.

' El paradigma relacional no se ubica en el mismo nivel que el resto de paradigmas (realismo positivista, constructivismo y convencionalismo), en cuanto que adopta una perspectiva morfogenética (M. ARCHER, 1995).

${ }^{2}$ Más concretamente, son identidades que se construyen mediante una relación suprafuncional de reciproca reflexividad teniendo en cuenta este principio general la distinción real de los términos está en la referencia mutua.

3 Un ejemplo concreto son las llamadas «politicas del tiempo» y la correspondiente planificación de los tiempos de la vida cotidiana (C. BELLONI, 1995: 307-316). En este caso, las relaciones entre conocimiento sociológico de las necesidades de los ciudadanos (especialmente de las mujeres) e intervención planificada (planes reguladores de los horarios de trabajo, de los servicios y de las relaciones de asistencia) presuponen cierta observación (hecha por un «sujeto en relación», con cretamente mujeres) y una cierta finalidad (la mujer como gestora y coordinadora de los tiempos de la vida cotidiana de la familia), que introducen todo el contexto
}

de las relaciones en las que se mueve, o intenta moverse, el observador-destinatario.

${ }^{4}$ No resulta aventurado decir que, en demografía, el análisis cualitativo está siendo actualmente introducido por investigadores con formación sociológica.

s Véase N. LuHMaNN (1989: 233-252), que, en pocas palabras, resume toda una literatura, también marxista y positivista (por ejemplo la de A. TOURAINE).

${ }^{6}$ Véase, por ejemplo, J. Bernardes (1986-1987). Nos encontramos ante definiciones pragmáticas, sin una reflexión teórica adecuada que pueda explicar cómo es posible cultural e institucionalmente la existencia de una familia donde ésta sea definida como convivencia de unas personas que se encuentran por casualidad para «afrontar juntos una parte del camino».

${ }^{7}$ Por ejemplo, forma parte del paradigma positivista decir que las relaciones con yugales pueden inspirarse en la igualdad hasta cierto punto; que la educación puede inspirarse en los deseos y aspiraciones de los hijos hasta un límite; que, en general, la influencia del Estado de Bienestar no puede traspasar unos límites si no quiere incurrir en efectos perversos. Limitar un planteamiento condicional 
a partir de posteriores condiciones no significa salir del marco epistemológico asumido. Por este motivo, una política social que tenga en cuenta los efectos perversos no consigue salir del positivismo. Se puede elaborar una mayor complejidad de condiciones permaneciendo en el positivismo. El paradigma constructivista dice algo más y diferente sobre el problema de los límites, en cuanto que se centra en las relaciones como fenómenos no comprensibles en el marco positivista.

${ }^{8}$ Recordemos los nombres de J. Habermas, C. Offe y G. Esping-ANdersen.

9 Así los denomina N. Lumnasin (1981: 253-273).

${ }^{10}$ Es normativamente arriesgada porque el riesgo es una norma positiva generalizada de innovación social (P. DONAT, 1989: cap. 4)

"Los ejemplos mas recientes los encontramos en los paises ex-comunistas del centro-este de Europa, que han optado por la vía del mercado. Véase, por ejemplo, el caso checo en M. HIRSL (1995).

${ }^{12}$ Un interesante y completo estudio de la morfogénesis social puede encontrarse en M. ARCHER (1995).

13 Como medio simbólico generalizado, la reciprocidad está presente y «circula» en todos los sistemas sociales: por ejemplo, en el sistema económico está presente como regla de equidad en los intercambios, en el sistema político aparece como regla de elección-control entre gobernantes y gobernados, en los sistemas de integración social (por ejemplo los mass media) se presenta como regla que hace que la influencia sea bidireccional. En la familia, la reciprocidad es «plena» porque concierne a la totalidad de la comunicación cotidiana.
14 Decimos de un alter ego, porque la política social no es la única que realiza esta función. Alter ego, en este sentido, también son el arte, la economía, la política, la religión, etc.

is La alusión al coupling (loose o tight) está presente en autores como G. BATEsoN, F. Varela y H. Maturana.

${ }^{16}$ Para este planteamiento, las interacciones son comportamientos («comunica. ción que tiene lugary), en la que los símbolos son signos o marcos carentes de un significado propio que ayude a ir más allá del puro acontecimiento perfor. mativo.

17 «Alargada» porque, a partir de las premisas epistemológicas señaladas, la poli. tica social sabe mirar más allá de su dependencia del Estado (P. DonaTr, 1993).

${ }^{18} \mathrm{La}$ familia permanece como una relación social suprafuncional, aunque sujeta a los desplazamientos de los límites entre dimensiones públicas y dimensiones privadas (P. Donan, 1989: cap. 1).

19 Véase R. SizA (1993).

${ }^{20}$ Sobre la interpretación relacional del esquema ÁGIL, véase P. Donan (1991: cap. 4).

${ }^{21}$ Conviene aclarar que me ubico en una posición crítica con respecto a la pers. pectiva de H. W山LKE (1986-1987). Aunque es necesario valorar el esfuerzo realizado por este sociólogo para desarrollar un programa relacional que, en buena medida, es deudor de la teoría sociológica de LUHMANN.

22 En esta línea se enmarcan las aportaciones de H. WILLKE (1987).

\section{Bibliografía}

ARCHER, M. (1995), Realist Social Theory: The Morphogenetic Approach, Cambridge Cambridge University Press.

BaLBo, L. (1977), Stato di famiglia, Milán: Etas.

BECKER, G. S. (1991), A Treatise on the Family, Cambridge Mass. and Londres: Harvard University Press.

Bernardes, J. (1987), «Doing Things with Words: Sociology and Familiy Policy Debates», en The Sociological Review, vol. 35, núm. 4: 679-702.

Boudon, R. (1982), La lógica de lo social, Madrid: Rialp.

DoNath, P. (1989), La famiglia come relazione sociale, Milán: Angeli.

- (1991), Teoria relazionale della società, Milán: Angeli.

- (1985) (comp.), Le politiche sociali nella società complessa, Milán: Angeli.

- (1993) (comp.), Fondamenti di politica sociale. Teorie e modelli, vol. 1, Roma: NIS; (comp.), Fondamenti di politica sociale. Obiettivi e strategie, vol. 2, Roma: NIS.

Donat, P., y Rossı, G. (1995), Le associazioni familiari in Italia, Milán: Angeli.

Elder, G. (ed.) (1984), Life Course Dynamics. Tajectories and Transitions 1968-1980, Nueva York: Comell University Press, Ithaca.

Ewald, F. (1986), L'État Providence, París: Grasset.

HIRsL, M., y otros (1995), Market Reforms and Social Welfare in the Czech Republic: A True Success Story?, Innocenti Occasional Papers Eps 50, Florencia.
Hurrelmann, K., y otros (eds.) (1987), Social Intervention: Potential and Constraints, Berlín: Gruyter.

LuHMANN, N. (1981), «Opportunismo e forme di programmazione nell'ammistrazione pubblica», en C. DONOLO y F. Fichera (comps.), Il goberno debole, Bari: De Donato: 253.273

- (1989), «ll sistema sociale famiglia», en La Ricerca Sociale, núm. 39, 1989 (tr. it. de «Sozialsystem Familie», en System Familie, 1, 1988: 75.91).

Pons, I. (1993), «Programación de la investigación social», en Cuadernos Metodológicos, núm. 8, Madrid: Centro de Investigaciones Sociológicas.

Rein, M., y PeatTiE, L. (1981), «Knowledge for Policy», en Social Service Review, vol. 55 , núm. 4.

Saraceno, C. (comp.) (1986), Età e corso della vita, Bolonia: Il Mulino.

SIzA, R. (1994), La programmazione e le relazioni sociali, Milán: Angeli.

S.MelSER, N. J. (ed.) (1988), Handbook of Sociology, Londres: Sage.

WILLKE, H. (1986), «Three Types of Legal Structure: The Conditional, the Purposive and the Relational Program», en G. Teubner (ed.), Dilemmas of Law in the Welfare State, Berlin: Gruyter: 280-298.

- (1987), «Observation, Diagnosis, Guidance. A Systems Theoretical View on Intervention», en K. Hurrelmann y otros (eds.), Social Intervention: Potential and Constraints, Berlín: Gruyter. 
